mented without further discussion by experts other than the nine members of the committee responsible for them. If this should take place, attention is likely to be focused on the possible retention of penicillin as a feed additive. The evidence against it is so questionable that its condemnation cannot be justified without further study.

The report proposes that veterinarians should retain full freedom in prescribing antibiotics and other antibacterial drugs, including the much disputed chloramphenicol, resistance to which in the typhoid bacillus is the spectre motivating present fears. It is to be hoped that the conclusions of the committee about the futility of trying to combat enteritis by mass antibiotic prophylaxis will be brought forcefully to the notice of the veterinary profession. Many other excellent but long-term recommendations are made with a view to the better study of epidemiology in animals and to improvements in methods of animal husbandry. It is well recognized that a certain type of trade in very young calves was largely responsible for recent disasters, and that intensive methods of rearing also carry risks which need to be intelligently countered. The use of antibiotics in feeding-stuffs is to be extended to calves. Antibiotic residues in foods are considered unimportant, but the search for a "marker" to denote the presence of antibiotics in milk from cows treated for mastitis should be continued (all the dyes so far tried are unsuitable in some way). It is proposed that under the Medicines Act one committee should have " overall responsibility for the whole field of use of antibiotics and related substances whether in man, animals, food preservation, or for other purposes." These and other proposals in this far-reaching document will give the departments concerned material for consideration for some years to come.

\section{Brucellosis Still Spreading}

Though brucellosis is a preventable disease, insufficient effort is being made to prevent it in Britain. The Scandinavian countries are clear of it, and many others are rapidly becoming so. In the United Kingdom only Northern Ireland has a satisfactory scheme of eradication, and the result is that over $97 \%$ of the eligible herds there have been certified as free of brucellosis. Yet in Great Britain up to the end of October this year only $6 \%$ of the herds had been registered as accredited. ${ }^{1}$ The figure for Scotland separately is $7 \% .^{1}$

As the disease in man is not generally notifiable, is difficult to diagnose, and is not often lethal, its prevalence in the community is impossible to estimate at all precisely. A figure of somewhere between 100 and 1,000 cases or even more a year has been discussed. ${ }^{2}$ At present informed opinion puts the total at about $800-1,000$. Though deaths are uncommon they do occur from time to time. In 1967, for instance, the latest year for which figures have been published for England and Wales, a man aged 60 and a woman of the same age died of the disease-the first in Lancashire and the second in Cheshire. ${ }^{3}$ But though death is uncommon disability can be severe, with long-continued weakness, malaise, sweating, and pains in the head, muscles, joints, and abdomen. Fever, rigors, and mental disturbance are reported in some cases. The signs and symptoms have been well reviewed by Dalrymple-Champneys ${ }^{4}$ and many cases reported on in the last two decades..$^{5-8}$
Man acquires infection mainly from cattle nowadays and to a much less extent from milk. This is because about $97 \%$ of the milk sold is heat-treated, which gives complete protection against transmission of brucellosis. But as the untreated $3 \%$ represents some 50 million gallons a year there is little doubt that some of this milk does spread the disease. ${ }^{\circ}$ Consequently, important though the provision of safe milk is, the main attack on brucellosis must come through its eradication from cattle. The failure of successive Governments to tackle the problem effectually has been criticized before in these columns, and the latest figures now given in Parliament ${ }^{1}$ show how backward Britain still is.

Nor is the slowness of the present scheme any guarantee of sureness. In fact there must be some anxiety lest the opposite is true. At page 550 of the B.M.7. this week Dr. R. J. Henderson describes how some farmers are deliberately selling and unwittingly buying cows infected with Brucella abortus. It should be stressed that his report is not in any sense an indictment of the farming community, the great majority of whom deplore and shun the practices he describes. But honesty can be expensive in farming as in other walks of life, and when a farmer who is struggling along finds that a cow he has bought comes out with brucellosis he is apt to react like not too scrupulous people who find a foreign coin in their change-pass it on quickly. Some farmers, in fact, lacking the financial resources or the craftsmanship that their occupation demands, are for ever buying cows in milk and selling them when they no longer yield a profit instead of going to the trouble of building up a milking herd over the years. Moreover, as the scheme for building up accredited herds progresses, so the number of infected animals being discovered and put up for sale increases. The result may well be, as Dr. Henderson suggests, that the number of infected herds will thus grow instead of diminish.

Though Dr. Henderson refers to the accredited herds scheme as the British eradication scheme, he is paying it a compliment it does not deserve. There is none of the compulsory detection and slaughter of cattle which other countries have carried out. A farmer in the accredited herds scheme who finds that one of his cows is infected must slaughter it if he wishes to remain in the scheme, but it is to his advantage to sell the animal in the open market. A true eradication scheme means compulsory measures to detect and slaughter infected cattle, with proper compensation to the farmer. All good farmers would welcome such a scheme, but successive Governments have temporized owing to the expense, and to give them their due they have been occupied in getting other diseases eradicated also, notably tuberculosis. But when does the application of a known remedy to prevent a substantial number of cases every year of a disabling and occasionally lethal disease cease to be too expensive ? As the disease is transmitted mainly by infected cattle, the chief sufferers from it are to be found in the farming community and their allies such as veterinary surgeons, so that in that sense it is largely an occupational disease. And it would certainly be hard to think of another occupation in which every year some

British Medical fournal, 1969, 4, 504.

2 British Medical fournal, 1966, 2, 63.

The Registrar General's Statistical Review of England and Wales, he Registrar General's Statistical Review of England
Part 1, Tables, Medical. London, H.M.S.O. 1967.

Dalrymple-Champneys, Sir W., Lancet, 1950, 1, 429, 477.

Dart, F. D., Morgan, A., and Lacey, B., British Medical fournal, 1951, 1, 1048.
. H., and Stote, C. L., British Medical fournal, 1953, 1, 914. ${ }^{6}$ Grant, G. H., and Stote, C. L., British Medical fournal,

Wallis, H. R. E., British Medical fournal, 1957, 1, 617.

On the State of the Public Health: Annual Report of the Chief Medical Officer of the Ministry of Fealth for the Year 1967. London. H.M.S.O. 1968.

.


hundreds of workers are allowed to contract a disease directly connected with their work when the cause and remedy are known. It is time that more stringent measures were introduced to stop the spread of this disease, especially as transmission is likely to increase rather than decline.

\section{Research into Clinical Endocrinology}

Britain is now the seventh most densely populated country in the world. Only Western Germany, the Lebanon, and Japan, Formosa, Belgium, and Holland have more inhabitants to the square kilometre. By the year 2000 the world's population is expected to be twice what it is now ; probably one-quarter of the 800,000 births in Britain every year are unplanned and unwanted. Giving these facts at an open-day in Edinburgh at the M.R.C. Clinical Endocrinology Unit, its director, Dr. J. A. Lorraine, said that they highlighted the importance of work on human fertility and contraception. Really effective, safe, and acceptable methods of contraception were urgently needed, but these would be found only by painstaking and thorough basic research in the laboratory.

From its inception in 1946 the Clinical Endocrinology Unit has always had a major interest in developing reliable methods of measuring hormone levels in body fluids. Once developed, these methods have then been applied to studying hormone metabolism in health and disease. Thus workers at the Unit have found that not only do girls before puberty have a cyclical pattern of oestrogen excretion but that their urinary gonadotrophin levels are similar to those in adult women. Similarly, they have shown that the menopause does not develop suddenly but occurs progressively over several years. Levels of luteinizing hormone ten times the normal figure have been found in women in their late thirties, even though they had no menopausal symptoms at all. Reassuringly, studies on women who had stopped taking oral contraceptives have indicated that the pill has no lasting effect on pituitary or ovarian function.

Besides close liaison with clinicians locally and elsewhere in Britain the Clinical Endocrinology Unit also has access to two beds in the Edinburgh Royal Infirmary. This has enabled it to study the hormonal aspects of conditions such as idiopathic hirsutism, dwarfism, and acromegaly. Since in hirsutism the urinary testosterone and epitestosterone levels are significantly higher than normal, it seems likely that excessive androgen production is an important feature in this condition. The next step is to discover whether the excess comes from the ovaries or the adrenals, so that the disorder can be treated effectively.

Studies in two conditions previously thought to be psychosomatic have indicated that endocrinological factors may also have an important role in some cases. In impotence testosterone excretion was found to be significantly below normal, and also not to show the usual rise after testicular function had been stimulated by an injection of chorionic gonadotrophin. In dysmenorrhoea the urinary oestrogen levels were found to be significantly lower than normal.

The final demonstration at Edinburgh was of the collaborative study between the Unit and St. Mary's Hospital in London on hormones and breast cancer. A few hours before mastectomy, patients with cancer of the breast are given an injection of oestrogen labelled with a small amount of tritium. About two-thirds of the tumours examined so far have been found to have concentrated the isotope compared with the blood or other tissues. Further work is planned to see whether this feature is related to the response of an individual tumour to hormone therapy and whether it can be used for deciding the best line of primary treatment.

In 23 years the Clinical Endocrinology Unit has achieved a high standing in the field of hormone metabolism in health and disease. This work seems likely to become increasingly relevant to contemporary problems, and in future the Unit's role should be of still greater clinical impcrtance.

\section{Suicide Prevention}

Until recently the idea that suicidal acts could be viewed in any other than their clinical context seemed strange to many doctors, and to some it still is. Yet during the last two decades organizations for preventing suicide have sprung up from the community in many countries, with and without medical blessing. By focusing on the suicidal crisis as an alarm signal, this new band of helpers is coming face to face with a host of personal and social ills which the clinical approach alone cannot fully reveal. They are also applying new methods of helping people in despair, ${ }^{12}$ and a recent statistical study suggests that they may be making an impact on the suicide rates. ${ }^{3}$

The suicide prevention agencies aim at attracting people who are at a loss to know whom to turn to for help. By inviting the use of the telephone for contacting ever-ready helpers they eliminate inhibitions which keep many people from outpatient clinics and doctors' surgeries.

The International Association for Suicide Prevention was officially established in 1965. It developed from an interdisciplinary working group founded by the Viennese psychiatrist Professor E. Ringel in 1960. Its main purpose is to serve as a forum for the interchange and the advancement of knowledge of suicidal behaviour. At present, the majority of the members are psychiatrists. It has been no small task to mould members of a variety of old and new professions, and voluntary workers with no professional affiliation except interest and experience in helping others, into a coherent and truly interdisciplinary organization in which no one group dominates the other. That it had been achieved became obvious at the recent London Conference, briefly reported last month, ${ }^{4}$ when an international gathering of doctors, clergymen, psychologists, social workers, and lay people working in suicide prevention centres discussed and presented research into many aspects of suicide.

The greater part of a day was spent on a survey of existing suicide prevention agencies all over the world, based on a questionary among the representatives of the association in 40 countries. The agencies vary widely. In Europe organizations have been more often started and headed by a psychiatrist ; in the United States clinical psychologists acted as pioneers. In some countries several rival organizations exist. Britain seems to be the only large country where one type of organization, the Samaritans, with 100 branches, is firmly established. Almost everywhere in Britain doctors have given

\footnotetext{
1 Fox, R., Lancet, 1962, 2, 1102.

2 Varah, C. (ed.), The Samaritans, 1965. London, Constable.

3 Bagley, C., Social Science and Medicine, 1968, 2, 1.

British Medical fournal, 1969, 4, 57.
} 